\title{
X-ray Fluorescence Analysis of Ferroalloys: Development of Methods for the Preparation of Test and Calibration Samples
}

\author{
Aurora G. Coedo, Maria Teresa Dorado, Carlos J. Rivero and Isabel G. Cobo \\ CENIM (CSIC), Gregorio del Amo 8, 28040 Madrid, Spain
}

\begin{abstract}
Methods were developed with a view to evaluating various sample preparation systems for use with X-ray fluorescence techniques in order to determine the major and minor components of ferroalloys, which are used as alloy-forming elements in steel making. The methods were compared in terms of simplicity and rapidity and these parameters were assessed in relation to the accuracy and precision of the results. The samples were prepared in three formats: metal samples, by dilution with iron and remelting in an induction furnace; pellets, by direct compaction of the ground material, and beads, by alkaline melting of the pre-oxidized sample. The tests used to optimize these methods were conducted with commercial ferroalloys, previously characterized by employing wet chemical and spectroscopic methods. Reproducibility and precision studies were conducted on samples obtained using each of the three sample preparation systems. The precisions (relative standard deviations) of major element determinations were $<0.8,<1.0$ and $<0.5 \%$ and those for minor elements were $<5,<5$ and $<3 \%$ for metal samples, pellets and beads, respectively. The accuracy of the methods was checked by analysing reference materials of each type of ferroalloy.
\end{abstract}

Keywords: Ferroalloy analysis; $X$-ray fluorescence spectrometry; sample preparation

\section{Introduction}

Steel-making practice involves the addition of various elements into the bath. Such elements are generally incorporated in the form of ferroalloys, the most common being ferrochromium, ferromanganese, ferrosilicon, ferrovanadium, ferromolybdenum, ferrotungsten, ferroniobium, ferrophosphorus, ferrotitanium and ferroboron. A precise and accurate knowledge of the chemical composition of ferroalloys serves a dual purpose: economic, owing to the high cost of the principal components, and technological, owing to the influence exerted by the degree of definition of their composition on the manufacturing of the steels, when setting the tolerance limits and their properties.

Ferroalloys, with regard to their physical presentation (which is conditioned by the manufacturing process itself) are not suitable for direct analysis and a preliminary treatment is necessary. This step, i.e., the sample preparation procedure, is one of the most critical phases of any analytical method.

In this study, the preparation of test samples was conducted with the following three procedures: obtaining metal samples, by diluting with iron and remelting in an induction furnace; formation of pellets, by directly compacting the sample previously ground to a certain grain size; and preparation of beads, by alkaline melting of the pre-oxidized sample. The calibration samples were prepared by the same system as used for the test samples, employing only one or two commercial ferroalloys of each of the types, by using different iron dilution ratios or different mixture proportions.

\section{Experimental}

\section{General Operating Procedure}

Scheme 1 shows the operating procedure followed in developing the working methods for the different types of ferroalloys.

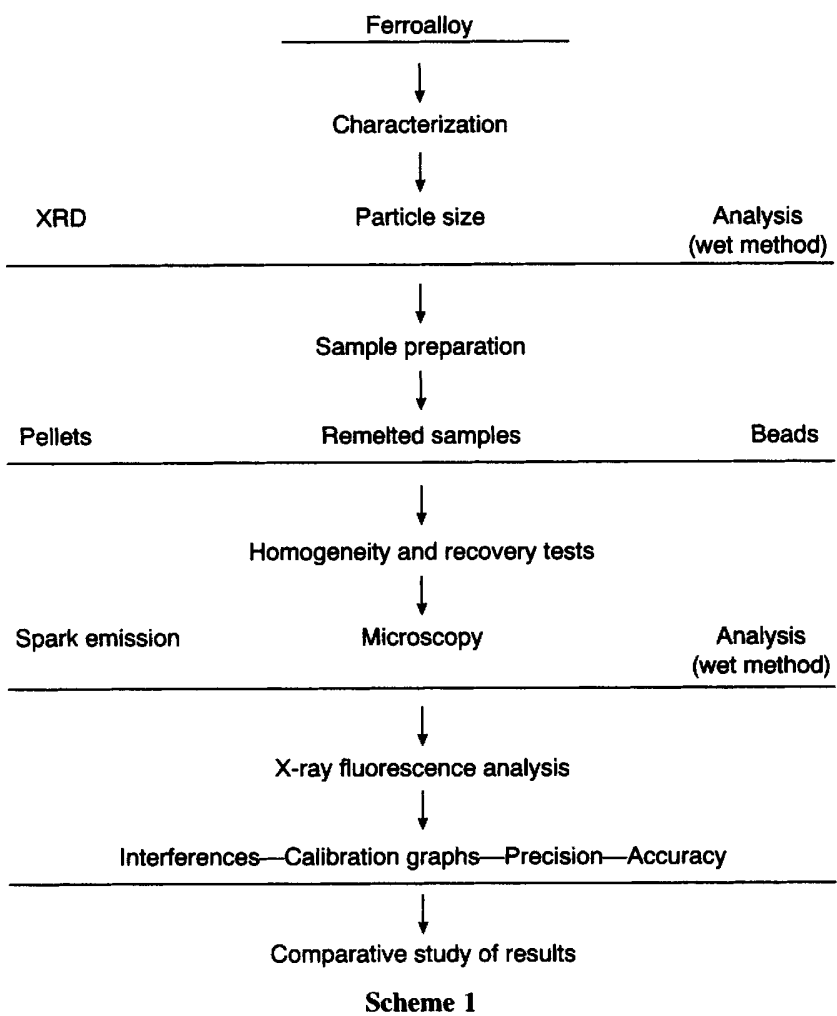

\section{Characterization of the Initial Materials}

Two commercial ferroalloys with as extreme compositions as possible were selected to develop the methods for each type of ferroalloy, with a view to covering the ranges of concentrations included in the International Organization for Standardization (ISO) specifications for each type. The materials were carefully characterized and analysed using X-ray diffraction (XRD) techniques and wet analytical methods. In all instances, approximately $2 \mathrm{~kg}$ of material with a particle diameter of less than $5 \mathrm{~cm}$ were used. The diameter of the particles was decreased to approximately $10 \mathrm{~mm}$ using a jaw breaker and then to less than $2 \mathrm{~mm}$ with a steel disc mill. 
Subsequently, the particle size was adjusted appropriately, depending on the sample preparation system used, with a tungsten carbide disc mill.

\section{Sample Preparation}

\section{Metal samples}

The test and calibration metal samples were obtained by melting the ferroalloy, previously mixed with iron, in a refractory crucible inside an induction furnace, provided with a direct reading automatic optical pyrometer. The molten metal was centrifuged and cast in an appropriate mould. Mullite-corundum refractory crucibles, of capacity approximately $20 \mathrm{ml}$, were used for the melting. To prevent the sample entering the pores of the uneven surface of the refractory, thus preventing it from melting, the inside walls of the refractory were covered with graphitized filter-paper. Once the components had been weighed to a precision of about $0.01 \mathrm{~g}$ and placed in the crucible, the latter was placed in the furnace stand so that when the inductor coils moved upwards, the crucible was concentric with them. The collector was placed perpendicular to the crucible, in order to receive the molten metal after the centrifugation process.

The collector was formed of a 'muzzle', made of the same heat-resistant material as the crucible, and a 'chill mould', consisting of two adjustable parts made from an alloy of $94 \%$ $\mathrm{Cu}$ and $6 \% \mathrm{Be}$. In line with the characteristics of the induction furnace and of the crucibles used, and also of the materials under study, the total mass of the remelted samples was $40 \mathrm{~g}$. Hence, the amounts of ferroalloy plus iron added up to this total amount. The samples obtained were mushroom-shaped, with a cylindrical head of about $30 \mathrm{~mm}$ diameter and $8 \mathrm{~mm}$ thick, and a stem about $12 \mathrm{~mm}$ in diameter and $6 \mathrm{~mm}$ high.

Table 1 gives the values selected for the melting parameters of each type of ferroalloy studied.

\section{Pellets}

For pellet preparation, a portion of the material was milled to a grain size of less than $74 \mu \mathrm{m}$. In order for the materials to have as similar a grain size as possible, the material was not milled too much below this grain size, the aim being for most of the particles to be between 32 and $74 \mu \mathrm{m}$.

In order to avoid overheating the material, $10 \mathrm{~g}$ portions of ferroalloy were milled for $30 \mathrm{~s}$ periods, in $10 \mathrm{~s}$ fractions, until the indicated grain size was attained.

Test and calibration samples were prepared by mixing $8 \mathrm{~g}$ of the ferroalloy with $5 \mathrm{ml}$ of $10 \%$ Elvacite (butyl methacrylate) in acetone, homogenizing manually until the acetone had evaporated completely. A layer of $8 \mathrm{~g}$ of boric acid was placed in an aluminium capsule $4 \mathrm{~cm}$ wide and $7 \mathrm{~mm}$ high, and then the $8 \mathrm{~g}$ sample with the binder was placed on top. A load of 40 ton $\mathrm{cm}^{-2}$ was exerted on the mixture for $20 \mathrm{~s}$ in a hydraulic press.

\section{Beads}

The process was performed manually, using a muffle furnace, and mechanically, with a bead machine. The following procedure was established: a small amount of alkaline flux and lithium tetraborate was placed in a platinum crucible, in such a way that the bottom and a few millimetres of the wall of the crucible were covered, and over it the sample and the oxidant were carefully mixed. During the oxidation phase, the sample mixture, flux and oxidant were heated progressively, without swirling, and when the flux began to melt it trapped the metal particles before the oxidation reaction started (hence contact between the reduced sample and the crucible was avoided). After oxidation, in a second step, the sample was fused with lithium tetraborate and during this step the crucible had to be oscillated to ensure complete homogenization of the mixture. The molten mass was poured on to nickel sheet $4.5 \mathrm{~cm}$ in diameter and $1 \mathrm{~mm}$ thick, or on to a platinum plate, preheated to dull red.

Table 2 lists the proportions of reactants and the oxidation and melting times and temperatures.

\section{Results and Discussion}

The industrial ferroalloys used to develop the methods and to obtain the samples for calibration were prepared and characterized in order to ensure homogeneous samples with as precise and accurate compositions as possible (it was essential to know their chemical composition with high precision in order to obtain accurate results from the corresponding calibration graphs). Wet chemical procedures ${ }^{1-3}$ were used for the analysis, and standardized methods were applied when they were available. To determine the major elements (ferroalloy grade), inductively coupled plasma methods ${ }^{4}$ were also employed in order to obtain results from two different techniques (classical and spectroscopic) and minimize the errors in the analytical results.

\section{Metal Samples}

The most important operational parameters in this system are the selection of the optimum dilution factor and the setting of the melting and casting temperatures. ${ }^{5,6}$

Table 1 Melting temperatures, melting times, casting temperatures, optimum dilutions ( $\mathrm{FeX}+\mathrm{Fe}$ ) and maximum tolerated contents of alloying elements

\begin{tabular}{|c|c|c|c|c|c|}
\hline $\mathrm{Fe}-\mathrm{X}$ & $\begin{array}{l}\text { Melting } \\
\text { temperature } /{ }^{\circ} \mathrm{C}\end{array}$ & $\begin{array}{l}\text { Melting } \\
\text { time/s }\end{array}$ & $\begin{array}{l}\text { Casting } \\
\text { temperature } /{ }^{\circ} \mathrm{C}\end{array}$ & $\begin{array}{l}\text { Optimum } \\
\text { dilution }\end{array}$ & $\begin{array}{l}\text { Maximum } \\
\text { major element } \\
\text { content }(\%)\end{array}$ \\
\hline $\mathrm{Fe}-\mathrm{Mo}$ & 1700 & 115 & 1500 & $15+25$ & 30 \\
\hline $\mathrm{Fe}-\mathrm{Nb}$ & 1850 & 130 & 1850 & $12+28$ & 24 \\
\hline $\mathrm{Fe}-\mathrm{V}$ & 1900 & 125 & 1700 & $12+28$ & 25 \\
\hline $\mathrm{Fe}-\mathrm{Cr}$ & 1750 & 130 & 1650 & $12+28$ & 30 \\
\hline $\mathrm{FeCr}-\mathrm{C}$ & 1550 & 120 & 1550 & $12+28$ & 30 \\
\hline $\mathrm{FeCrSi}$ & 1600 & 120 & 1600 & $8+32$ & $12(\mathrm{Si})$ \\
\hline $\mathrm{Fe}-\mathrm{W}$ & 1900 & 112 & 1800 & $8+32$ & 20 \\
\hline $\mathrm{Fe}-\mathrm{Si}$ & 1600 & 120 & 1400 & $6+34$ & 15 \\
\hline FeSiMn & 1400 & 115 & 1400 & $6+34$ & $25-\mathrm{Si}+\mathrm{Mn}$ \\
\hline $\mathrm{Fe}-\mathrm{Mn}$ & 1400 & 115 & 1350 & $15+25$ & 42 \\
\hline FeMn-C & 1300 & 110 & 1150 & $15+25$ & 36 \\
\hline $\mathrm{Fe}-\mathrm{P}$ & 1250 & 112 & 1100 & $6+34$ & 5 \\
\hline $\mathrm{Fe}-\mathrm{Ti}$ & 1700 & 110 & 1500 & $4+36$ & 10 \\
\hline $\mathrm{Fe}-\mathrm{B}$ & 1800 & 110 & 1450 & $0.75+39.25$ & 2 \\
\hline
\end{tabular}


Certain conditions governed the setting of the content of the maximum alloy-forming element in the samples, namely obtaining highly homogeneous samples that did not crack or break during casting or during the turning or polishing processes. At this point of the study, efforts were focused on defining a general system for melting all the ferroalloys, with specific guidelines for each particular instance. The over-all aim was to meet the following objectives: (a) maximum concentration of ferroalloy in the test sample to minimize analytical errors (greater sensitivity in determining the minor elements and greater accuracy in determining the main components); (b) a high percentage of recovered material; (c) ideal melting conditions for composition of the mixtures (the $\mathrm{Fe}-\mathrm{X}$ binary phase equilibrium diagrams made it possible to

Table 2 Oxidation times and temperatures (oxide beads)

\section{Oxidation process reactants}

\begin{tabular}{lllll}
\multicolumn{2}{c}{ reactants } & & \multicolumn{2}{c}{ Oxidation } \\
\cline { 5 - 5 } Reactant & Amount/g & $\mathrm{Fe}-\mathrm{X}$ & Temperature/ ${ }^{\circ} \mathrm{C}$ & Time/min \\
& & $\mathrm{Fe}-\mathrm{Mo}$ & $650-700$ & 4 \\
& & $\mathrm{Fe}-\mathrm{Nb}$ & $700-750$ & 6 \\
& & $\mathrm{Fe}-\mathrm{V}$ & $700-750$ & 6 \\
$\mathrm{FeX}$ & $0.2500^{*}$ & $\mathrm{Fe}-\mathrm{Cr}{ }^{\dagger}$ & $750-800$ & 8 \\
$\mathrm{Sr}\left(\mathrm{NO}_{3}\right)_{2}$ & $0.750^{*}$ & $\mathrm{Fe}-\mathrm{Cr}-\mathrm{Si}$ & $700-750$ & 5 \\
$\mathrm{Na}_{2} \mathrm{CO}_{3}$ & 2.000 & $\mathrm{Fe}-\mathrm{W}$ & $700-750$ & 6 \\
$\mathrm{Li}_{2} \mathrm{~B}_{4} \mathrm{O}_{7}$ & 1.000 & $\mathrm{Fe}-\mathrm{Si}$ & $650-700$ & 4 \\
$\mathrm{NaI}$ & 0.020 & $\mathrm{Fe}-\mathrm{Si}-\mathrm{Mn}$ & $650-700$ & 5 \\
& $\ddagger$ & $\mathrm{Fe}-\mathrm{Mn}{ }^{\dagger}$ & $800-850$ & 5 \\
& & $\mathrm{Fe}-\mathrm{P}$ & $800-850$ & 5 \\
& & $\mathrm{Fe}-\mathrm{Ti}$ & $650-700$ & 6 \\
& & $\mathrm{Fe}-\mathrm{B}$ & $650-700$ & 5
\end{tabular}

* The test samples and oxidizing reactive were used with a grain size of $<100 \mu \mathrm{m}$.

$\dagger$ The test sample mass for samples with carbon contents $>0.1 \%$ must be corrected in accordance with their losses through ignition:

$$
\text { test sample mass } / g=\frac{0.2500 \times 100}{100-\% \mathrm{C}}
$$

末 Once oxidized, the sample was fused with $5.000 \mathrm{~g}$ of $\mathrm{Li}_{2} \mathrm{~B}_{4} \mathrm{O}_{7}$ at $1200^{\circ} \mathrm{C}$ for $4 \mathrm{~min}$. pre-set the melting temperatures and to predict the possible phases that would appear in the samples); (d) good structural homogeneity, free from physical defects and with sufficient mechanical resistance to prevent them from breaking or deteriorating with time, and to withstand the sandpapering and polishing processes prior to analysis; (e) good chemical homogeneity in the distribution of both the major and minor components; and (f) short preparation time and ease of repeating similar tests.

Table 1 gives, in addition to the selected melting time and temperature parameters, the maximum major element contents that can be present in the samples without heterogeneity, breaking or fracture problems, and the optimum dilution factor. This last value was selected with a view to obtaining samples with major element contents below the established maxima (whatever the grade of the ferroalloy to be analysed), and covering any composition within the ISO specifications (in this way, for analysing any ferroalloy, it will suffice to prepare the test samples with this optimum dilution factor).

The calibration samples were prepared in the same way as the test samples from a single industrial ferroalloy. Iron dilutions were performed to different extents until the desired range of concentrations had been covered, taking into account the composition of the initial ferroalloy and the concentration range in which the alloying element is found in these materials.

Table 3 lists the major element contents of the industrial ferroalloys used to prepare the calibration samples and the maximum and minimum dilution factors used (these extreme dilution factors cover the whole range of concentrations desired) and the equivalent percentage (corresponding to a ferroalloy analysed from a test sample prepared with the optimum dilution factor).

Five intermediate dilutions were prepared between the minimum and maximum dilution factors for each type of ferroalloy tested, in order to have at least seven different compositions to establish accurately the calibration graphs. The test samples were prepared from 'optimum dilution', a dilution with which any ferroalloy grade can be analysed, within the same type, with the established calibration ranges. Three samples of each composition were prepared under identical working conditions, and six samples with the

Table 3 Major element contents, dilutions for calibration samples and percentage of major element equivalent to samples with the optimum dilution factor. The optimum dilution factor for each ferroalloy is indicated in Table 1

\begin{tabular}{|c|c|c|c|c|c|}
\hline \multirow[b]{2}{*}{$\begin{array}{l}\text { Commercial } \\
\text { ferroalloy }\end{array}$} & \multirow[b]{2}{*}{$\begin{array}{l}\text { Alloying } \\
\text { element }(\%)\end{array}$} & \multicolumn{2}{|c|}{ Dilution $(X+F e)$} & \multirow{2}{*}{\multicolumn{2}{|c|}{$\begin{array}{l}\text { Major element in ferroalloy }(\%) \\
\text { (optimum dilution) }\end{array}$}} \\
\hline & & Minimum & Maximum & & \\
\hline $\begin{array}{l}\mathrm{Fe}-\mathrm{Mo} \\
\mathrm{Fe}-\mathrm{Nb} \\
\mathrm{Fe}-\mathrm{V} \\
\mathrm{Fe}-\mathrm{Cr} \\
\mathrm{Fe}-\mathrm{Cr}-\mathrm{C}\end{array}$ & $\begin{array}{l}70.70 \pm 0.22 \\
67.70 \pm 0.20 \\
78.01 \pm 0.25 \\
64.19 \pm 0.18 \\
66.60 \pm 0.16\end{array}$ & $\begin{array}{r}12+28 \\
8+32 \\
5+35 \\
8+32 \\
8+32\end{array}$ & $\begin{array}{l}18+22 \\
14+26 \\
13+27 \\
18+22 \\
16+24\end{array}$ & $\begin{array}{l}56.56 \\
45.13 \\
32.50 \\
42.80 \\
44.40\end{array}$ & $\begin{array}{l}84.83 \\
78.97 \\
84.50 \\
96.30 \\
88.80\end{array}$ \\
\hline $\begin{array}{c}\mathrm{FeCrSi}^{(\mathrm{Cr})^{*}} \\
(\mathrm{Si})^{*}\end{array}$ & $\begin{array}{l}32.34 \pm 0.18 \\
48.51 \pm 0.16\end{array}$ & $2.5+37.5$ & $15+25$ & $\begin{array}{l}10.10 \\
15.5\end{array}$ & 60.63 \\
\hline $\mathrm{FeSi}$ & $77.10 \pm 0.25$ & $0.5+39.5$ & $7.5+32.5$ & 6.42 & 96.45 \\
\hline $\begin{array}{c}(\mathrm{Mn})^{*} \\
\text { FeSiMn } \\
(\mathrm{Si})^{*}\end{array}$ & $\begin{array}{l}66.50 \pm 0.25 \\
16.60 \pm 0.22\end{array}$ & $3.5+36.5$ & $13+27$ & 39.06 & 100.00 \\
\hline $\begin{array}{l}\mathrm{Fe}-\mathrm{Mn} \\
\mathrm{Fe}-\mathrm{Mn}-\mathrm{C} \\
\mathrm{Fe}-\mathrm{P} \\
\mathrm{Fe}-\mathrm{W} \\
\mathrm{Fe}-\mathrm{Ti} \\
\mathrm{Fe}-\mathrm{B}\end{array}$ & $\begin{array}{l}85.90 \pm 0.11 \\
76.00 \pm 0.13 \\
24.75 \pm 0.16 \\
76.20 \pm 0.21 \\
68.50 \pm 0.16 \\
18.26 \pm 0.14\end{array}$ & $\begin{array}{c}13+27 \\
13.7+26.3 \\
4+36 \\
7+33 \\
1+39 \\
0.40+39.6\end{array}$ & $\begin{array}{l}17+23 \\
16.5+23.5 \\
7+33 \\
9+31 \\
5+35 \\
0.90+39.1\end{array}$ & $\begin{array}{r}74.45 \\
64.91 \\
16.46 \\
66.67 \\
17.72 \\
9.76\end{array}$ & $\begin{array}{l}97.33 \\
83.60 \\
28.87 \\
85.72 \\
85.62 \\
21.86\end{array}$ \\
\hline
\end{tabular}

* \% alloying element in the commerical ferroalloy considered. 
'optimum dilution', with a view to conducting precision studies for verifying the repeatability of the sample preparation system.

The minor element calibration samples were also prepared to cover the ISO specifications. These elements were incorporated by adding the elements either from specifically prepared cast iron or from pure metals or the appropriate alloys. In any event, the set of samples obtained easily covered the ranges of concentrations in which the corresponding elements are normally present in the respective types of ferroalloys.

The total amount of sample recovered was in all instances above $99 \%$ (>39.6 $\mathrm{g}$ recovered from a total of $40 \mathrm{~g}$ ).

The samples all had homogeneous structures, in accordance with the corresponding equilibrium diagrams of the component compounds. ${ }^{7}$ They also had good chemical homogeneity, which was verified by spark emission spectrometry as follows. Four discharges were applied to each of the two samples of the extreme compositions (for each type of ferroalloy), at different points on the surface, and the emission of each element present, both major and minor, was measured. Then, to check the homogeneity in depth, two cuts were made in the samples, parallel to the surface and each 3 $\mathrm{mm}$ thick, and four discharges were applied to the surfaces exposed and the emissions were measured. The relative standard deviations $\left(s_{\mathrm{r}}\right)$ corresponding to the 12 measurements of each element in each sample were in all instances less than $1 \%$, except for $\mathrm{Al}$ and $\mathrm{Ti}$, for which the values were $>10 \%$.

Samples with the extreme compositions were employed to verify the propotions of the different elements. The determinations were made on the material in the form of chips, using wet analytical methods. These analyses revealed the correct incorporation of most of the components during the remelting process. The only exceptions were $\mathrm{Al}$ and $\mathrm{Ti}$, because of the difficulties with the incorporation and homogeneous distribution of these two elements in the iron matrix. Their presence also hindered the determination of $\mathrm{Si}$ (an element that causes no difficulties when $\mathrm{Al}$ and $\mathrm{Ti}$ are absent) because they favoured the reduction of the silica of the crucible, producing silicon contamination in the sample. As the interaction between the crucible and the ferroalloy varied with the type of crucible and its porosity, tests were performed with other types of crucibles of different compositions. Circona (zirconium and aluminium silicate) crucibles react with the sample in the same way as the mullite-corundum crucibles, but they do not withstand such high temperatures as the latter and break more easily. Similar behaviour to that of the circona crucibles was noted with silica crucibles, which generally break before the melting has been completed. Consequently, the final tests were performed with mullite-corundum crucibles. All operating parameters were kept constant for each type of ferroalloy, to minimize and control the possible modifications of the molten mixtures.

With ferrochromes and ferromanganeses, the carbon contents were found to have an important influence on the X-ray fluorescence measurements of the major elements (Cr or $\mathrm{Mn}$ ). These measurements increased in line with the carbon content, and it was necessary to correct the contents found for the major elements in terms of the sample carbon content.

To establish the corresponding corrections, two series of ferrochrome and ferromanganese samples were prepared, with a constant $\mathrm{Cr}$ and a constant $\mathrm{Mn}$ content, respectively, and variable carbon contents. With these samples, and the sets of samples prepared to establish the calibration graphs, both for the high-carbon materials and for materials with carbon contents of less than $0.1 \%$, it was possible to define the correction factors. Once the corrections had been made, the results for all the samples prepared with constant $\mathrm{Cr}$ or $\mathrm{Mn}$ content and variable carbon contents (obtained from the calibration graph corresponding to samples with a carbon content of less than $0.1 \%$ ) had $s_{\mathrm{r}}<0.5 \%$.

\section{Pellets}

Although the advantages inherent in the melting of the samples are well known (with a view to eliminating matrix interferences), studies were conducted to evaluate the direct compaction sample preparation method with respect to speed of performance, ease of handling and absence of diluents. It must not be forgotten that in materials of this type, given that their origin is similar for each type of ferroalloy (because they came from a previous melting process), their mineralogical state was very similar and it was easier to correct for the matrix interferences, which then depended exclusively on the concentrations of interfering elements and not on the nature of the components. In this preparation system the grinding times and grain size were the parameters that had to be carefully set and monitored. ${ }^{8}$

The calibration samples were prepared by compacting mixtures, in five different proportions, of two ferroalloys, with the maximum available difference in compositions, to cover the whole range of possible concentrations within the specifications typical of each type of ferroalloy. Where the ISO specifications were not fully covered in this way, the ranges were completed with pellets prepared from reference materials, previously conditioned to the indicated grain size.

Table 4 lists the major element contents of the materials used to obtain the calibration samples for each type of ferroalloy. Samples corresponding to mixtures of the two corresponding industrial ferroalloys were inserted between the extreme contents of the calibration standards.

By using calibration samples that cover the whole range of concentrations desired, and all of them prepared from materials of similar grain size, matrix corrections can be made and suitable calibration graphs can be obtained for the direct analysis of these materials.

The stability of the compacted samples was checked by making measurements throughout the study. No significant variations were found that could be attributed to deterioration caused by the time that had elapsed since they were prepared.

\section{Beads}

Methods based on obtaining beads (oxide glasses) are widely used in the analysis of ferroalloys by X-ray fluorescence spectrometry because this system minimizes both the mineralogical influences and those due to the particle size and interelemental effects. Various methods have been described for obtaining beads with optimum characteristics for the analysis of ferroalloys by this sample preparation system..$^{9-13}$ The selection of the oxidant and of the oxidation and melting times and temperatures were the critical points of the system. The methods developed by Staats ${ }^{11}$ and Petin et al. ${ }^{12}$ were selected as the basis for this study. After tests to verify the reproducibility and precision, the ease of application and the times used, the oxidation system was simplified using $\mathrm{Sr}\left(\mathrm{NO}_{3}\right)_{2}$ at temperatures between 650 and $800^{\circ} \mathrm{C}$ as the sole oxidizing agent. The tests were conducted using the same industrial ferroalloys as were used to develop the methods with remelted metal samples and compacted pellets. The bead calibration graphs were obtained from the beads prepared with five different proportions of two ferroalloys with the most extreme compositions available (the same as used for pellet calibration samples). If the initial ferroalloys did not cover the whole range of concentrations that appear in the ISO specifications, complementary samples were prepared by adding the corresponding elements in the form of oxides. 
Between six and ten samples of scaled compositions were prepared to obtain each calibration graph.

To evaluate the behaviour of the different ferroalloys during the oxidation process, samples were prepared exclusively from oxides, with compositions similar to those of the industrial ferroalloys used to develop the methods. The comparative study of the results with both types of sample was used to assess the efficiency of the melting process and it showed that it is possible to make calibrations with primary materials, with well known stoichiometries, so minimizing the total errors. ${ }^{14}$

The beads obtained were highly stable with time. They were kept individually in plastic bags and inside desiccators (at a constant temperature) and were measured periodically throughout the study; the results revealed no changes that could be attributed to their deterioration.
A study was made of the deterioration suffered by the platinum crucibles due to the presence of elements in the metallic state (reduced) and to their reaction with the crucible walls, despite the fact that contact was minimized with the crucible loading system mentioned. It was concluded that when the process is performed manually (six platinum crucibles in normal laboratory use were employed) for all the ferroalloys studied (except for the ferrochrome), the mass losses of the platinum crucibles vary from 1 to $4 \mathrm{mg}$ in each melting, hence these values depend on the characteristics of the samples and on the original state of the crucibles (depending on whether they have been attacked beforehand to a greater or lesser extent). The attacks were more significant with the ferrochromes, especially for the highcarbon ferrochromes. In any event, it must be stressed that, throughout the study (with a total of 1000 fusions), none of the

Table 4 Major element contents of samples employed for preparing calibration pellets

\begin{tabular}{|c|c|c|c|c|c|}
\hline $\mathrm{Fe}-\mathrm{X}$ & Sample & $\begin{array}{l}\text { Major element } \\
\text { content }(\%)\end{array}$ & $\mathrm{Fe}-\mathrm{X}$ & Sample & $\begin{array}{l}\text { Major element } \\
\text { content }(\%)\end{array}$ \\
\hline $\mathrm{Fe}-\mathrm{Mo}$ & $\begin{array}{l}\text { FeMo-PC } \\
\text { FeMo-II } \\
\text { IRSID-508 } \\
\text { EUR-578 }\end{array}$ & $\begin{array}{l}70.70 \\
63.56 \\
59.56 \\
72.23\end{array}$ & $\mathrm{Fe}-\mathrm{Nb}$ & $\begin{array}{l}\text { FeNb-AZMA } \\
\text { CRM-576 }\end{array}$ & $\begin{array}{l}78.01 \\
50.16\end{array}$ \\
\hline $\mathrm{Fe}-\mathrm{Cr}$ & $\begin{array}{l}\mathrm{FeCr}-\mathrm{I}-\mathrm{c} \\
\mathrm{FeCr}-\mathrm{T}-\mathrm{c} \\
\mathrm{CRM}-507 \\
\text { CRM-554 }\end{array}$ & $\begin{array}{l}66.60 \\
58.39 \\
70.30 \\
74.60\end{array}$ & $\mathrm{Fe}-\mathrm{Mn}$ & $\begin{array}{l}\text { FeMn-c } \\
\text { FeMn }\end{array}$ & $\begin{array}{l}76.00 \\
85.90\end{array}$ \\
\hline $\mathrm{Fe}-\mathrm{Cr}-\mathrm{Si}$ & $\begin{array}{l}\mathrm{FeCrSi}-073 \\
\mathrm{FeCr}-\mathrm{III}\end{array}$ & $\begin{array}{l}\mathrm{Cr}: 32.34-\mathrm{Si}: 48.51 \\
\mathrm{Cr}: 64.19-\mathrm{Si}: 1.05\end{array}$ & $\mathrm{Fe}-\mathrm{Si}-\mathrm{Mn}$ & $\begin{array}{l}\text { FeSiMn-c } \\
\text { FeSi-I }\end{array}$ & $\begin{array}{l}\mathrm{Mn}: 66.50-\mathrm{Si}: 16.60 \\
\mathrm{Si}: 45.32-\mathrm{Mn}: 0.48\end{array}$ \\
\hline $\mathrm{Fe}-\mathrm{V}$ & $\begin{array}{l}\text { FeV-9 } \\
\text { CRM-577 }\end{array}$ & $\begin{array}{l}78.01 \\
50.16\end{array}$ & $\mathrm{Fe}-\mathrm{W}$ & $\begin{array}{l}\mathrm{FeW}-7 \\
\mathrm{FeW}-8\end{array}$ & $\begin{array}{l}76.20 \\
87.31\end{array}$ \\
\hline $\mathrm{Fe}-\mathrm{Si}$ & $\begin{array}{l}\text { FeSi-c } \\
\text { FeSi-I } \\
\text { FeSiMn-c }\end{array}$ & $\begin{array}{l}77.10 \\
45.32 \\
66.50\end{array}$ & $\begin{array}{l}\mathrm{Fe}-\mathrm{Ti} \\
\mathrm{Fe}-\mathrm{P}\end{array}$ & $\begin{array}{l}\text { FeTi-22 } \\
\text { BCS-234/4 } \\
\text { FeP-A } \\
\text { FeP-M }\end{array}$ & $\begin{array}{l}68.50 \\
38.2 \\
24.75 \\
17.20\end{array}$ \\
\hline
\end{tabular}

Table 5 Calibration parameters. Concentration $=D+E I$, where $D=$ intercept on the ordinate/slope, $E=1 /$ slope and $I=$ intensity

\begin{tabular}{|c|c|c|c|c|c|c|c|c|c|}
\hline \multirow[b]{2}{*}{$\mathrm{Fe}-\mathrm{X}$} & \multicolumn{3}{|c|}{ Remelted samples } & \multicolumn{3}{|c|}{ Pellets } & \multicolumn{3}{|c|}{ Beads } \\
\hline & $D$ & $E$ & $s$ & $D$ & $E$ & $s$ & $D$ & $E$ & $s$ \\
\hline Mo & -1.1250 & 0.2710 & 0.1000 & 11.2754 & 0.3244 & 0.1984 & 1.0302 & 0.4261 & 0.1088 \\
\hline $\mathrm{Nb}$ & 0.3597 & 0.2519 & 0.1594 & 0.8219 & 0.2670 & 0.1999 & 1.1215 & 1.2635 & 0.1085 \\
\hline $\mathrm{Cr}$ & 1.9054 & 0.2706 & 0.0679 & 42.2069 & 0.1887 & 0.2069 & 0.5690 & 1.5090 & 0.1326 \\
\hline $\mathrm{V}$ & 1.3809 & 0.5220 & 0.1035 & -99.315 & 0.9710 & 0.1890 & -2.9702 & 3.1543 & 0.1044 \\
\hline W & 0.4441 & 1.2768 & 0.0605 & 64.9524 & 0.3011 & 0.1393 & -1.5216 & 1.8010 & 0.1209 \\
\hline $\mathrm{Si}$ & -0.0261 & 0.4045 & 0.0469 & 28.9502 & 0.1449 & 0.1308 & 0.2310 & 4.4745 & 0.1053 \\
\hline $\mathrm{Mn}$ & 3.3734 & 0.3013 & 0.0750 & -44.373 & 0.2537 & 0.1217 & 10.8171 & 1.1190 & 0.1205 \\
\hline $\mathrm{P}$ & 0.4564 & 0.0216 & 0.0653 & 35.6223 & 0.3571 & 0.1156 & 0.7337 & 1.9660 & 0.1105 \\
\hline $\mathrm{Ti}$ & 1.2698 & 0.4030 & 0.1607 & -0.8672 & 0.1704 & 0.1501 & -1.9005 & 3.2012 & 0.1396 \\
\hline
\end{tabular}

Table 6 Precision tests

\begin{tabular}{|c|c|c|c|}
\hline \multirow[b]{2}{*}{ Test } & \multicolumn{3}{|c|}{$\mathrm{X}$-ray fluorescence } \\
\hline & Remelting & Pellets & Beads \\
\hline Ten measurements on same sample $\left[s_{\mathrm{r}}(\%)\right]$ & $<0.20$ & $<0.20$ & $<0.10$ \\
\hline Ten measurements on 6 samples $\left[s_{\mathrm{r}}(\%)\right]$ & $0.20-0.40$ & $0.20-0.50$ & $0.10-0.25$ \\
\hline Major element tolerances $(\%)^{*}$ & $\begin{array}{r}\text { From } \pm 0.25 \\
\text { to } \pm 0.40\end{array}$ & $\begin{array}{r}\text { From } \pm 0.30 \\
\text { to } \pm 0.55\end{array}$ & $\begin{array}{r}\text { From } \pm 0.15 \\
\text { to } \pm 0.20\end{array}$ \\
\hline Minor element precision $\left[s_{\mathrm{r}}(\%)\right]$ & $\begin{array}{l}<5 \\
\text { ex.Al-Ti }\end{array}$ & $<5$ & $<3$ \\
\hline
\end{tabular}

${ }^{*} T= \pm t\left(s / \vee_{n}-\right.$ ). The confidence intervals were calculated for a $95 \%$ confidence level and two determinations. The $t$ and $s$ values were obtained from ten measurements of each of the six samples with the same composition and prepared under the same operating conditions. 
crucibles used had to be repaired. With the 'bead machine', only two crucibles were used. These were utilized simultaneously for making beads of other materials, and a total of around 250 fusions of ferroalloys were made; although the masses of the crucibles were not monitored, it was concluded that both were slightly attacked but were in perfect condition for use.

\section{$X$-ray Analysis}

All the series of calibration samples prepared (with the three systems employed), both for the alloying elements and for the minor elements, were measured by X-ray fluorescence spectrometry. Table 5 lists the calibration parameters corresponding to the alloying elements of each type of ferroalloy and the standard deviation $(s)$ (dispersion of the experimental data in relation to the regression obtained from the theoretical values).

The reproducibility of these analytical systems was tested by measuring one sample ten times and also by measuring each of the six samples of each series ten times (prepared under the same conditions and with the same composition). The ranges of values obtained for the standard deviations are given in Table 6.

The accuracy of the procedures was checked by comparing various reference materials for each type of ferroalloy. The results agreed in all instances, within the levels of precision provided by the operating methods followed.

\section{Conclusions}

As a general conclusion, the levels of precision and accuracy attained in the analysis of ferroalloys by X-ray fluorescence spectrometry depend both on the sample preparation system followed and on the quality of the calibration samples used. The selection of the sample preparation system depends both on the laboratory facilities available and on the need for speed and precision. Complete series of calibration samples can be obtained from a single ferroalloy (in a metal sample system) or from two ferroalloys (pellet and bead systems) with the maximum difference of compositions available.

Major elements can be determined (from two measurements and for a confidence level of $95 \%$ ) with confidence intervals from \pm 0.25 to $\pm 0.40 \%$, from \pm 0.30 to $\pm 0.55 \%$ and from \pm 0.15 to $\pm 0.20 \%$ using metal samples, pellets and beads, respectively. As regards the minor elements, the precisions $(n=6)$ were $s_{\mathrm{r}}<5,<5$ and $<3 \%$, respectively.

In terms of the time taken to prepare the samples (with a particle size of $<2 \mathrm{~mm}$, that is, the size used in the remelting system) and ease of performance, the remelting and compaction systems are very easy to perform and take about 15 and 8 min per sample, respectively, whereas the beads system takes approximately $20 \mathrm{~min}$ and requires greater care.

In terms of cost, the compaction system involves no significant non-recoverable costs, whereas in the remelting and bead systems these costs can be considered to be similar (disposable crucibles for remelting and reactants and periodical recovery of the platinum crucibles for the beads).

This paper is part of a research project financially supported by the European Community for Coal and Steel (CECA), No. 7210-GD/932. We are grateful to Dr. G. Staats and Dr. J. Petin for their help concerning bead preparation.

\section{References}

1 Standard Methods for Chemical Analysis of Ferroalloys, Annual Book of ASTM Standards, E-31-85, ASTM, Philadelphia, PA, 1985, vol. 03.05, Sect. 3.

2 Soudan, P., Techniques de l'Ingénieur, 1990, Metallurgie, vol. 1, pt. 2 , p. 266.

3 Cunningham, A., and Chanbasha, A. R., paper presented at British Steel BISRA Chemists' Conference, 1990.

4 Gómez Coedo, A., Dorado López, M. T., and Vindel Maeso, A., Spectrochim. Acta, Part B, 1986, 41, 193.

5 Grimaldi, R., Meuci, A., and Randi, G., in L'Analysi Strumentale delle Ferroleghe, ed. Etas, G., Kompass, Milan, 1975.

6 Willay, G., Rapport Exterieur IRSID RE. 1182, May, 1985.

7 Binary Alloy Phase Diagrams, ed. Bayer, H. E., American Society for Metals, Metals Park, OH, 1986.

8 Ambrose, A. D., The X-Ray Fluorescence Analysis of Iron Ore Sinter. A Study of Some Aspects of Specimen Preparation, BISRA open report, MG/D/671/70.

9 Kawamura, K., J. Iron Steel Inst. Jpn., 1974, 60, 1892.

10 Wittman, A., Willey, G., and Seffer, R., Préparation de Perles pour l'Analyse par FX, Commission des Communautés Européennes, Luxembourg, 1979, EUR. 6288j.

11 Staats, G., Arch. Eisenhüttenwes., 1974, 45, 693.

12 Petin, J., Wagner, W., and Bentz, F., Steel Res., 1985, 56, 215.

13 Dirheimer, J. M., Les fondants et l'Analyse des Alliages Metalliques. Fluxes and Analysis of Ferroalloys, CCE-CETAS, Luxembourg, 1987.

14 Staats, G., Fresenius' Z. Anal. Chem., 1993, 315, 1.

Paper 3/02881J

Received May 20, 1993 Accepted July 5, 1993 